\title{
FEBRE AFTOSA E VOLATILIDADE DOS PREÇOS DO PRODUTOR DE CARNE SUÍNA ${ }^{1}$
}

\author{
Thiago Fleith Otuki ${ }^{2}$ \\ Celso Leonardo Weydmann ${ }^{3}$ \\ Fernando Seabra ${ }^{4}$
}

Resumo. Focos da doença aftosa voltaram a ser registrados no Brasil em 2004 e 2005, o que provocou embargos às exportações brasileiras de carne suína. Neste estudo, investiga-se a presença de volatilidade dos preços pagos ao produtor da carne suína, após o aparecimento da enfermidade. Por meio de um modelo GARCH, incorporado de uma variável indicativa da presença da febre aftosa no modelo, confirmou-se a hipótese de que a enfermidade provocou grande volatilidade nos preços da carne suína. Concluise que a febre aftosa causa dificuldades não apenas pelos prejuízos devidos ao embargo às exportações, mas também porque acentua a volatilidade dos preços internos, o que traz instabilidade no planejamento dos negócios e na renda dos produtores.

Palavras-chave: febre aftosa, carne suína, volatilidade, GARCH.

\section{Introdução}

Surtos de febre aftosa têm sido recorrentes no Brasil, e o maior número de focos aconteceu nos anos 70. Programas de controle das doenças foram desenvolvidos, o que pode ter contribuído para que, de 1998 a 2001, a Organização Mundial de Saúde Animal (OIE) ${ }^{5}$ reconhecesse 15 estados como áreas livres da doença com vacinação. Nos dois anos seguintes, não houve notificação da doença, que ressurgiu em 2004 e

Recebido em 12/03/09; Aceito em 12/06/09.

2 Mestre pelo Programa de Pós-Graduação em Economia da Universidade Federal de Santa Catarina (UFSC). E-mail: thiagootuki@ig.com.br.

3 Professor Doutor do Programa de Pós-Graduação em Economia da Universidade Federal de Santa Catarina (UFSC).E-mail: celsolw@cse.ufsc.br.

4 Professor Doutor do Programa de Pós-Graduação em Economia da Universidade Federal de Santa Catarina (UFSC).E-mail: seabra@cse.ufsc.br.

5 A OIE tem como objetivos garantir a segurança sanitária animal para o comércio internacional e, principalmente, assegurar a transparência do status dos países quanto às doenças animais. 
2005 no Paraná e Mato Grosso do Sul, componentes da área de reconhecimento da OIE, e também no Pará e Amazonas.

A reação dos mercados internacionais à existência dos focos de aftosa em 2004-2005 foi de grande expressão, o que torna o estudo da febre aftosa, nesse período, de especial interesse neste trabalho. Segundo a ABIPECS (2007), 30 países suspenderam importações de carne suína em 2005 e outros 50 impuseram restrições às exportações brasileiras de carne bovina (ABIEC, 2006). Dados da ABIPECS mostram que o crescimento anual do volume exportado de carne suína, em 2004, 2005 e 2006 , foi, respectivamente, de $3,4 \%, 23 \%$ e $-15 \%$, os quais foram inferiores ao crescimento médio de $59 \%$, nos quatro anos anteriores (20002003).

A retração das exportações teve reflexos no mercado interno. A carne destinada à exportação foi estocada pela indústria e, esgotada essa alternativa, foi colocada no mercado interno. Os produtores, por sua vez, tiveram que manter os animais nas propriedades além do tempo ideal de abate, o que dificultou o ajuste da produção às alterações do mercado. A ampliação da oferta de carne suína contribuiu para que os preços do produtor apresentassem maior variabilidade e tendência de queda. Além disso, dada a concentração das empresas processadoras de carne suína, dentre as quais as três maiores representam mais de $30 \%$ do mercado de suínos (ABIPECS, 2006), o comportamento dos preços resultaria de uma atuação não cooperativa destas em frente à crise nas vendas externas. De fato, dados da Fundação Getúlio Vargas (FGV) mostram que, no período anterior ao da ocorrência da febre aftosa (jan. 2000 a set. 2004), o preço real da arroba de carne suína no Brasil elevou-se apenas $1 \%$, enquanto caiu $14 \%$ no período em que houve focos da doença (entre out. 2004 e dez. 2005). A instabilidade dos preços, por sua vez, representada pelo coeficiente de variação, elevou-se de 11,6 (no primeiro período) para 14,7 (no segundo período), um aumento de $25 \%$.

Maior instabilidade nos preços da carne suína gera dificuldades na previsão dos negócios e instabilidade na renda dos produtores, o que pode justificar 
uma investigação mais rigorosa para determinar as suas reais dimensões. A questão colocada neste estudo é se o surgimento da febre aftosa em 2004-05, que resultou em aumento das restrições de carne suína por parte dos países importadores, também resultou em grandes oscilações nos preços dos produtores, caracterizando o fenômeno de aglomeração de volatilidade. Para isso, procura-se avaliar a volatilidade dos retornos dos preços recebidos pelos produtores de carne suína, antes e depois do surgimento da febre aftosa, nos anos de 2004 e 2005.

A investigação da volatilidade no mercado agrícola é uma abordagem que gera crescente interesse. Pode-se citar o caso da carne suína, nos trabalhos de Jones (2005) e Harper et al. (1999); da carne bovina, em Natcher et al. (1999); do café em grão no Brasil, em Silva et al. (2005); e de vários grãos, como em Swaray (2002) e Cuddington et al. (2003). A avaliação dos impactos econômicos da febre aftosa também é extensa, podendo-se citar, no caso brasileiro, os trabalhos de Faria et al. (2006), Lima et al. (2005), Machado et al. (2006), além de autores que estudaram a contribuição no impacto da febre aftosa em outros mercados, como Hsu et al. (2005), Blake et al. (2002), Jarvis et al.(2005) e Roh et al. (2006).

A próxima seção trata da febre aftosa no Brasil, seguida pela descrição do mercado e das exportações de carne suína. A seção 3 descreve o método e a seção 4, os resultados. As conclusões estão na seção 6.

\section{A febre aftosa no Brasil}

A febre aftosa (Foot and Mouth Disease - FMD) é uma enfermidade viral, contagiosa, que afeta naturalmente animais domésticos e selvagens, como bovinos, bubalinos, ovinos, caprinos e suínos (Pituco, 2001).

Os prejuízos da doença, segundo Lima et al. (2005), originam-se da queda na produção por conta do abate dos animais infectados e dos custos públicos e privados para indenizar produtores e efetivar o controle e a erradicação. Para esses autores, a enfermidade é o principal fator 
restritivo de maior entrada de carne brasileira in natura nos maiores mercados do mundo, totalizando perdas anuais de cerca de US $\$ 8$ bilhões para a carne bovina e de US\$7 bilhões para a carne suína.

O Brasil tem uma longa história de convivência com a febre aftosa. A doença foi relatada, pela primeira vez, em 1895 e, em anos recentes, o auge do número de focos detectados foi na década de 70 , diminuindo sensivelmente após essa data (Figura 1).

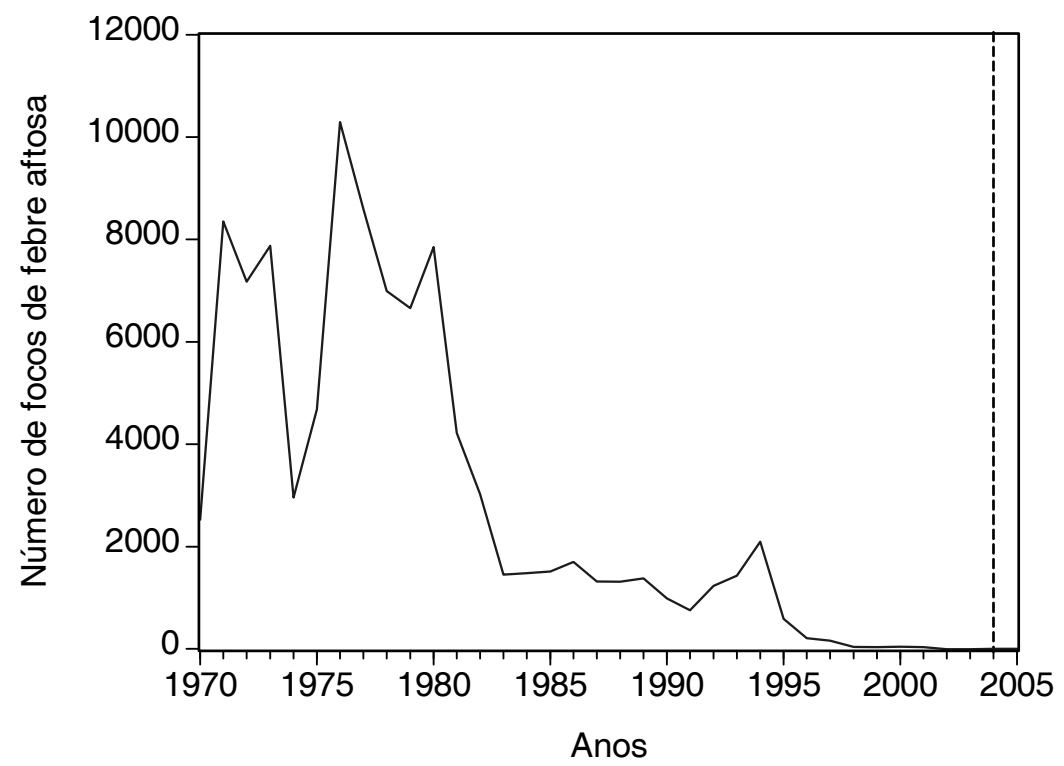

Figura 1 - Número de focos de febre aftosa no Brasil, 1970-2005 Fonte: Lyra e Silva (2004).

Para Lima et al.(2005), a criação do Programa Nacional de Erradicação da Febre Aftosa (PNEFA), em 1992, teve impacto na queda do número de focos. O Brasil é considerado pela OIE como livre da febre suína africana, da doença vesicular dos suínos e da influenza aviária, todas da 
Lista $\mathrm{A}^{6}$, da Instituição. Em relação à febre aftosa, em 1998, aquela instituição reconheceu os estados de SC e RS como área livre da febre aftosa com vacinação; em 2000, foi a vez do DF, PR, GO, MT, SP e MG; em 2001, abrangeu SE, ES, RJ, BA, MS, TO, MG, MT, SP, GO; e em 2003 e 2005, os estados de RO e AC, respectivamente.

Focos da doença foram registrados, em junho e setembro de 2004, no Pará e Amazonas, respectivamente, e, em outubro de 2005, no Mato Grosso do Sul e Paraná.

\section{Mercado e exportações de carne suína}

O relatório da ABIPECS (2008) mostra que a produção brasileira de carne suína, em 2008, foi de aproximadamente 3.000 mil toneladas, das quais cerca de $17 \%$ foram exportadas, totalizando 529 mil toneladas. $\mathrm{O}$ Brasil ocupa o quarto lugar tanto na produção mundial quanto na exportação. Os dados disponíveis mostram que as exportações brasileiras representaram 12,5\% das exportações mundiais em 2004, estimando-se que essa participação tenha se elevado para $14,2 \%$ e $14,3 \%$, em 2005 e 2006, respectivamente (ABIPECS, 2004). Os três maiores importadores de carne suína brasileira, em 2008, foram Rússia (42,5\%), Hong Kong $(20,4 \%)$ e Ucrânia $(9,3 \%)$. O estado do Rio Grande do Sul liderou os volumes exportados $(44,8 \%)$, seguido por Santa Catarina $(31,8 \%)$ e Paraná $(5,9 \%)$.

Em 2004, a Rússia fechou seu mercado para as carnes brasileiras, impondo restrições às importações de animais vivos, carne suína, carne bovina e produtos e subprodutos de carne crua de suínos e bovinos procedentes de oito estados brasileiros (MT, MS, GO, SP, MG, PR, SC e RS). Segundo a ABIPECS (2007), o surgimento de focos da doença no MS (municípios de Japorã e Eldorado), em fins de 2005, fez com que 30 países suspendessem as importações de carne suína do Brasil, com

O OIE classifica as doenças animais com base em seu significado socioeconômico e de saúde pública. A lista A contém doenças transmissíveis com potencial de difusão muito sério e rápido, sem levar em consideração as fronteiras nacionais. 
impacto mais significativo nas exportações de 2006, principalmente nos meses de março e abril.

A Tabela 1 mostra que o crescimento anual médio do volume exportado de carne bovina e suína entre 2000 e 2003 , que era de $33 \%$ e $60 \%$, respectivamente, manteve-se em 2004, para a carne bovina, e caiu 3,4\% para a carne suína. Em 2005, as exportações de carne bovina e suína continuaram a crescer em ritmo inferior à média dos anos anteriores, $16 \%$ e $23 \%$, respectivamente. Em 2006, os volumes exportados de carne bovina recuperaram o ritmo de crescimento $(61 \%)$, enquanto houve decréscimo de $16 \%$ para a carne suína.

Tabela 1 - Exportações de carne bovina e suína do Brasil, 2000-2006, milhões de toneladas

\begin{tabular}{|c|c|c|c|c|}
\hline Ano & $\begin{array}{c}\text { Carne } \\
\text { Bovina }\end{array}$ & $\begin{array}{c}\text { Variação } \\
\text { anual }\end{array}$ & $\begin{array}{c}\text { Carne } \\
\text { Suína }\end{array}$ & $\begin{array}{c}\text { Variação } \\
\text { Anual }\end{array}$ \\
\hline 2000 & 455 & 100 & 135 & 100 \\
\hline 2001 & 632 & 139 & 260 & 193 \\
\hline 2002 & 733 & 116 & 476 & 183 \\
\hline 2003 & 1054 & 144 & 491 & 103 \\
\hline 2004 & 1386 & 131 & 508 & 103 \\
\hline 2005 & 1610 & 116 & 625 & 123 \\
\hline 2006 & 2588 & 161 & 528 & 84 \\
\hline
\end{tabular}

Fonte: ABIEC (2006) e ABIPECS (2006).

Portanto, como visto acima, os focos de febre aftosa no Brasil, em 200405 , deram origem a barreiras não-tarifárias impostas pelos principais países importadores. Esse fato foi, de alguma forma, agravado pela excessiva dependência das exportações do mercado russo, que absorveu $65 \%$ do volume de carne exportado em 2005 (ABIPECS, 2006), e cuja decisão de embargo, baseada em idiossincrática interpretação das autoridades daquele país acerca do protocolo sanitário Brasil-Rússia e das regras da OIE, não foi entendida pelas organizações brasileiras do setor (ABIPECS, 2006). 
O término do embargo, que depende de requisitos técnicos e negociações políticas do Brasil com cada país importador, torna-se, assim, uma fonte de incerteza acerca do mercado doméstico de carne suína. Nesse sentido, a hipótese central deste estudo é que a eclosão da febre aftosa, em 2004-05, tenha gerado restrições às exportações de carne suína brasileira e, em consequência, houve elevação da volatilidade do preço no mercado interno.

\section{Método de análise}

São utilizadas, neste trabalho, duas séries de preços relativas ao período de 06/1984 a 09/2006; o preço médio recebido pelo produtor (Brasil) em corte de $15 \mathrm{~kg}$, conforme FGV/Agroanalysis (2006), e os preços pagos aos produtores de Chapecó/SC, suíno não tipificado $(\mathrm{kg})$, publicado pelo $\operatorname{ICEPA}^{7}$ (2006).

A série de preços pagos aos produtores de Chapecó/SC foi, primeiramente, transformada no atual padrão monetário, para as observações anteriores a junho de 1994. A outra série já está disponível, em reais (R\$), no IPEA (2006). As séries de preços foram deflacionadas pelo IPA-OG ${ }^{8}$ - carnes e pescados - índice (junho 2006=100), da FGV/ Conjuntura Econômica.

Para serem submetidas à análise, as séries de preços foram transformadas em taxas de retorno calculadas pela expressão

$$
r_{i, t}=\ln P_{i, t}-\ln P_{i, t-1}
$$

em que $r_{i, t}$ é o retorno do preço da carne suína, no mês t; $P_{i, t}$, preço da carne suína, em t; e $P_{i, t-1}$, preço da carne suína, em t-1. A adoção da

7 Instituto de Planejamento e Economia Agrícola de Santa Catarina.

8 Índice de preço por atacado - oferta geral. 
série de retornos, ao invés dos preços, tem duas razões: primeiro, em termos teóricos, busca-se relacionar o retorno obtido na atividade com a volatilidade desse retorno (em linha, portanto, com a teoria de ativos ${ }^{9}$ ); segundo, por razões estatísticas, uma vez que a série em retorno tende a ser estacionária ${ }^{10}$.

A análise contempla, inicialmente, as estatísticas descritivas das séries, como o cálculo da média, a mediana, o desvio-padrão, a variância, o coeficiente de curtose, a assimetria e os testes de normalidade e estacionariedade das séries. Para testar a hipótese de normalidade, aplicase o teste de Jarque-Bera. As séries de retornos foram avaliadas quanto à estacionariedade, por meio do teste ADF (Dickey-Fuller Aumentado).

Foram estimados também os coeficientes de autocorrelação e autocorrelação parcial dos retornos e retornos ao quadrado, para encontrar evidências de efeitos ARCH. Da mesma forma, para constatar que a série de retornos apresenta um padrão $\mathrm{ARCH}$, realizou-se o teste ARCH-LM (ARCH - Multiplicador de Lagrange) nos resíduos dos modelos autorregressivos, ajustados à média condicional dos retornos.

Em relação à especificação dos modelos, foram realizados alguns procedimentos. O primeiro passo consiste no ajuste de um modelo autorregressivo, do tipo

$$
r_{i, t}=c+\sum_{i=1}^{k} \phi_{i} r_{t-i}+\varepsilon_{t}
$$

em que, $r_{i, t}$ é o retorno dos preços da carne suína; $r_{t-i}$, retorno dos preços na defasagem i; e $\varepsilon_{t}$, erro da equação. Os erros gerados pela

\footnotetext{
9 A teoria de ativos diz respeito ao argumento básico em finanças, aplicado também a outros ativos nãofinanceiros, de que existe relação direta entre risco e retorno esperado de um ativo. Esta abordagem foi apresentada, originalmente, por Sharpe (1964).

${ }^{10}$ Estas razões seguem as adotadas por Tsay (2002) apud Silva (2005).
} 
equação da média condicional servem de variável exógena para a estimativa do modelo $\mathrm{GARCH}^{11}$. O número de defasagens de cada equação é definido pelo critério de Akaike.

O segundo passo, após a especificação para as equações da média condicional, é a modelagem da volatilidade dos retornos condicionais, ajustando-se os modelos GARCH. Dessa forma, estima-se, nas duas séries, um modelo GARCH para descrever o comportamento da volatilidade dos retornos dos preços, ignorando os possíveis efeitos do foco de febre aftosa (setembro de 2004) sobre a variância condicional no período. Assim, foram estimados os coeficientes dos seguintes modelos:

$$
\begin{aligned}
& \sigma_{S B R t}^{2}=\alpha_{0}+\sum_{i=1}^{p} \alpha_{i} \varepsilon_{t-i}^{2}+\sum_{j=1}^{q} \beta_{i} \sigma_{t-j}^{2}, \\
& \sigma_{S S C t}^{2}=\alpha_{0}+\sum_{i=1}^{p} \alpha_{i} \varepsilon_{t-i}^{2}+\sum_{j=1}^{q} \beta_{i} \sigma_{t-j}^{2},
\end{aligned}
$$

em que $\sigma_{S B R t}^{2}$ e $\sigma_{S S C t}^{2}$ são, respectivamente, as variâncias condicionais em $\mathrm{t}$ dos retornos do preço do suíno (Brasil) e suíno (SC); $\sigma_{t}^{2}$, variância condicional em t; $\alpha_{0}$, termo constante; $\varepsilon_{t-i}^{2}$, erro observado ao quadrado em t $-\mathrm{i} ; \sigma_{t-j}^{2}$, variância condicional em t $-\mathrm{j} ; \alpha_{i}$, parâmetro associado ao termo $\varepsilon_{t-i}^{2} ; \beta_{j}$, parâmetro associado ao termo $\sigma_{t-j}^{2} ;$ p e q, defasagens ótimas determinadas pelo critério de Akaike.

\footnotetext{
${ }^{11}$ O modelo GARCH (Generalized Autoregressive Conditional Heteroskedasticity), desenvolvido por Bollerslev (1986), é derivado do modelo ARCH (Autoregressive Conditional Heteroskedasticity), formulado anteriormente por Engle (1982). A diferença fundamental é que o modelo GARCH inclui, como variável explicativa, os valores defasados da variância esperada (isto é, valores da variável dependente defasada), o que exige um método interativo de estimação.
} 
Destacadas essas especificações, mas com o intuito de captar o possível impacto da febre aftosa na volatilidade, como terceiro passo, uma variável dummy, AFTOSA, é incluída à especificação GARCH, da seguinte forma:

$$
\begin{gathered}
\sigma_{S B R t}^{2}=\alpha_{0}+\delta_{3} \text { Aftosa }+\sum_{i=1}^{p} \alpha_{i} \varepsilon_{t-i}^{2}+\sum_{j=1}^{q} \beta_{i} \sigma_{t-j}^{2} \\
\sigma_{S S C t}^{2}=\alpha_{0}+\delta_{4} \text { Aftosa }+\sum_{i=1}^{p} \alpha_{i} \varepsilon_{t-i}^{2}+\sum_{j=1}^{q} \beta_{i} \sigma_{t-j}^{2}
\end{gathered}
$$

A variável dummy AFTOSA é igual a 1 (um), nas observações na amostra iniciadas em setembro de 2004, e igual a 0 (zero), nas demais observações. Os parâmetros dos modelos serão estimados pelo método de máxima verossimilhança, empregando uma distribuição normal, pois a maioria das modelagens de variância condicional utiliza tal método, dado que os parâmetros estimados são não-tendenciosos e consistentes. O algoritmo de otimização utilizado foi o Berndt-Hall-Hall-Hausmann (BHHH), conforme recomendado por Bollerslev (1986).

\section{Análise dos resultados}

\subsection{Análise dos preços e estatísticas dos retornos}

Ao analisar os gráficos da Figura 2, pode-se perceber o comportamento dos preços e dos retornos das duas séries. No período de análise, a economia brasileira passou por regimes monetários diferentes, resultado da implementação dos Planos Econômicos nas décadas de 80 e 90. 
Thiago Fleith Otuki, Celso Leonardo Weydmann \& Fernando Seabra

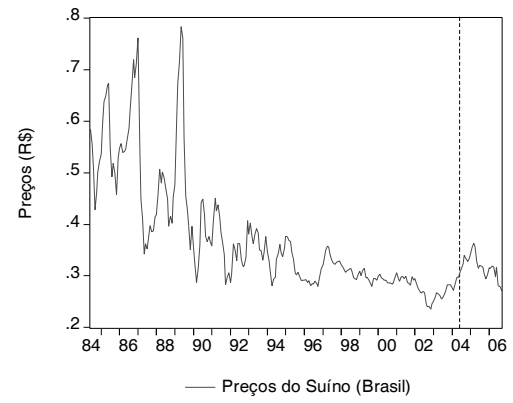

(1)

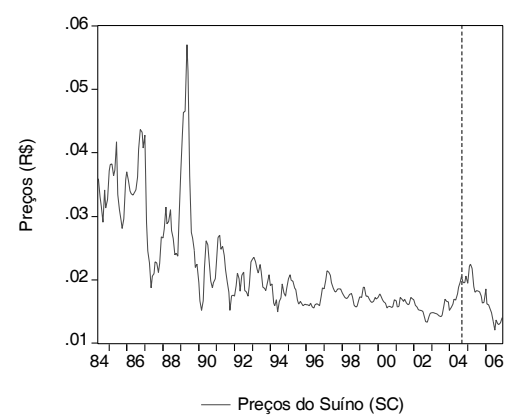

(3)

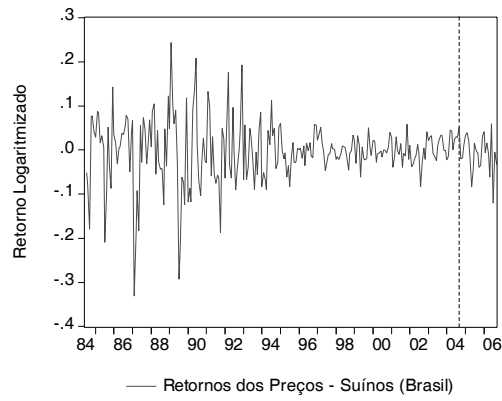

(2)



(4)

Figura 2. Gráficos dos preços e retornos do suíno - Brasil e SC, 06/ 1984 a 09/2006

Notas:

(1) Preço médio recebido pelo produtor (Brasil) - suíno (06/1984 a 09/2006)/ Fonte: IPEA (2006).

(2) Retorno dos preços (Brasil) - suíno (06/1984 a 09/2006)/Fonte: Dados da Pesquisa.

(3) Preço médio recebido pelo produtor (SC) - suíno (06/1984 a 11/2006)/Fonte: ICEPA-SC (2006).

(4) Retorno dos preços (SC) - suíno (06/1984 a 11/2006)/Fonte: Dados da pesquisa. 
Os preços no longo prazo apresentaram tendência de queda, fruto dos ganhos de produtividade, e redução nos custos das cadeias produtivas, conforme indicam os estudos de Macedo (2007) e Carvalho et al. (2006).

No período pré Plano Real, a variabilidade dos preços foi maior, seguida por maior estabilidade na segunda metade da década de 90 até 2004. A linha vertical, tracejada em todos os gráficos, indica a data (setembro de 2004) do início dos focos de febre aftosa. Percebe-se o aumento na volatilidade dos retornos.

A Tabela 2 contém as estatísticas descritivas das séries.

Tabela 2 - Estatísticas descritivas das séries de retornos dos preços de carne suína, 06/1984 a 11/2006

\begin{tabular}{lcc}
\hline Estatísticas & Brasil & SC \\
\hline Média & $-0,002887$ & $-0,003711$ \\
Mediana & $-0,001205$ & $-0,005948$ \\
Máximo & 0,243701 & 0,274486 \\
Mínimo & $-0,330893$ & $-0,390016$ \\
Desvio-padrão & 0,068392 & 0,083050 \\
Coef. Variação & $-23,68964$ & $-22,379413$ \\
Assimetria & $-0,660407$ & $-0,453366$ \\
Curtose & 7.025 .512 & 6.471 .577 \\
Jarque-Bera & 1.996 .859 & 1.442 .962 \\
Valor P (JB) & 0,000000 & 0,000000 \\
\hline
\end{tabular}

Fonte: dados da pesquisa.

As estimativas não diferem muito entre si, em ambas as séries. Os retornos médios negativos refletem a tendência de queda nos preços. A grande amplitude das séries reflete a grande variabilidade, que é corroborada pelos altos coeficientes de variação. Os coeficientes de assimetria indicam uma distribuição com caudas longas, e os coeficientes de curtose revelam séries leptocúrticas. As estimativas do valor-p implicam que se rejeite a hipótese de que o termo do erro se aproxima da distribuição normal, em ambas as séries. 
Como pode ser visto na Tabela 3, os testes ADF mostram que, em ambas as séries, a hipótese nula de raiz unitária pode ser claramente rejeitada, uma vez que o valor do teste é bastante inferior ao seu valor crítico. Note-se que as especificações reportadas na Tabela 3, com constante e com ou sem tendência, referem-se ao resultado do teste com uma defasagem e com um número ótimo de defasagens, determinada a partir de uma estrutura com até 12 meses (o que tende a reduzir o efeito de movimentos sazonais). A defasagem ótima foi de 5 meses.

Tabela 3 - Testes de raiz unitária para os retornos dos preços (ADF), 06/1984 a 11/2006

\begin{tabular}{l|c|l|c}
\hline Série & Defasagens & \multicolumn{1}{|c}{ Modelo } & Resultado do teste ADF \\
\hline & 1 & c/ constante & $-12.35156^{*}$ \\
Retornos dos preços - & 5 & c/ constante & $-12.35156^{*}$ \\
Suíno (Brasil) & 1 & c/ constante e tendência & $-12.32958^{*}$ \\
& 5 & c/ constante e tendência & $-12.32958^{*}$ \\
\hline & 1 & c/ constante & $-12.49322^{*}$ \\
Retornos dos preços - & 5 & c/ constante & $-12.49322^{*}$ \\
Suíno (SC) & 1 & c/ constante e tendência & $-12.46964^{*}$ \\
& 5 & c/ constante e tendência & $-12.46964 *$ \\
\hline
\end{tabular}

*Significante a 1\%; Valores críticos do ADF com 1\% de significância são: -3,46 (com constante e sem tendência); e -3,99 (com constante e com tendência).

Fonte: Dados da pesquisa.

Na especificação da equação do retorno do preço do suíno (e, logo, também para o teste ADF), o efeito sazonal não foi considerado. Uma dummy sazonal para dezembro (mês de pico de consumo de carne suína) foi estimada como não-significativa na determinação do retorno do preço do suíno no BR e SC.

Conforme as Tabelas 4 e 5, as estimativas dos coeficientes de autocorrelação e autocorrelação parcial para os retornos e retornos ao quadrado indicam a existência de efeitos ARCH nas séries. 
Tabela 4 - Estimativas dos coeficientes de autocorrelação das séries de retornos. Suíno (Brasil) e Suíno (SC), 06/1984 a 11/2006

\begin{tabular}{lcccc}
\hline Retornos & Suíno - Brasil & Estatística Q & Suíno - SC & Estatística Q \\
\hline CA (1) & 0.268 & $19.377(0.000)$ & 0.262 & $18.762(0.000)$ \\
CA (2) & 0.067 & $20.581(0.000)$ & 0.012 & $18.800(0.000)$ \\
CA (3) & 0.032 & $20857(0.000)$ & -0.013 & $18.846(0.000)$ \\
CA (4) & -0.143 & $26.448(0.000)$ & -0.151 & $25.152(0.000)$ \\
CA (5) & -0.263 & $45.377(0.000)$ & -0.153 & $31.616(0.000)$ \\
\hline CAP (1) & 0.268 & $19.377(0.000)$ & 0.262 & $18.762(0.000)$ \\
CAP (2) & -0.006 & $20.581(0.000)$ & -0.061 & $18.800(0.000)$ \\
CAP (3) & 0.017 & $20857(0.000)$ & 0.000 & $18.846(0.000)$ \\
CAP (4) & -0.168 & $26.448(0.000)$ & -0.158 & $25.152(0.000)$ \\
CAP (5) & -0.203 & $45.377(0.000)$ & -0.078 & $31.616(0.000)$ \\
\hline
\end{tabular}

Notas:

*CA = Coeficiente de autocorrelação $/ *$ *AP $=$ Coeficiente de autocorrelação parcial.

() Os números entre parênteses na primeira coluna indicam a defasagem.

$O$ valor $p$ da estatística $Q$ de Ljung-Box está entre parênteses.

Fonte: Dados da pesquisa.

Tabela 5 - Estimativas dos coeficientes de autocorrelação das séries de retornos ao quadrado. Suíno (Brasil) e Suíno (SC), 06/ 1984 a 11/2006

\begin{tabular}{lcccc}
\hline Retornos $^{2}$ & Suíno - Brasil & Estatística Q & Suíno - SC & Estatística Q \\
\hline CA $(1)^{\star}$ & 0.269 & $19.545(0.000)$ & 0.262 & $18.812(0.000)$ \\
CA (2) & 0.083 & $21.398(0.000)$ & 0.063 & $19.905(0.000)$ \\
CA (3) & 0.158 & $28.196(0.000)$ & 0.144 & $25.583(0.000)$ \\
CA (4) & 0.083 & $30.066(0.000)$ & 0.087 & $27.660(0.000)$ \\
CA (5) & 0.277 & $51.085(0.000)$ & 0.085 & $29.657(0.000)$ \\
\hline CAP (1) & 0.269 & $19.545(0.000)$ & 0.262 & $18.812(0.000)$ \\
CAP (2) & 0.011 & $21.398(0.000)$ & -0.006 & $19.905(0.000)$ \\
CAP (3) & 0.143 & $28.196(0.000)$ & 0.138 & $25.583(0.000)$ \\
CAP (4) & 0.005 & $30.066(0.000)$ & 0.017 & $27.660(0.000)$ \\
CAP (5) & 0.271 & $51.085(0.000)$ & 0.061 & $29.657(0.000)$ \\
\hline
\end{tabular}

Notas:

*CA = Coeficiente de autocorrelação $/ *$ *AP $=$ Coeficiente de autocorrelação parcial.

( ) Os números entre parênteses na primeira coluna indicam a defasagem.

$O$ valor $p$ da estatística $Q$ de Ljung-Box está entre parênteses.

Fonte: Dados da pesquisa. 
Com a definição das equações da média condicional, efetuou-se o teste ARCH-LM nos resíduos desses modelos. Os resultados na Tabela 6, em sua especificação com distribuição quiquadrada ou $\mathrm{F}$, mostram valores de probabilidade que indicam a rejeição da hipótese nula de variância condicional homocedástica. Logo, pode-se modelar a variabilidade condicional (ex-ante) dos preços da carne suína, conforme a especificação de um modelo ARCH/GARCH.

Tabela 6 - Teste ARCH-LM (Multiplicador de Lagrange) para as séries de retornos, 06/1984 a 11/2006

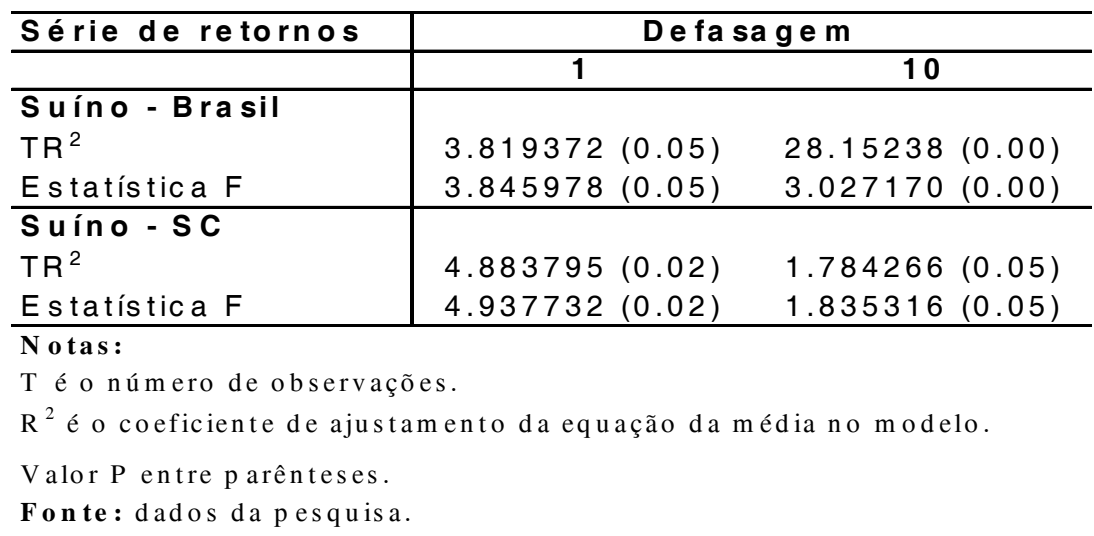

\subsection{Resultados das estimativas dos modelos}

Conforme os resultados reportados na Tabela 7, os parâmetros dos modelos GARCH, aplicados às séries de retornos dos preços do suíno (Brasil) e suíno (SC), exceto as constantes das equações da média e variância, são estatisticamente significativos e dentro das restrições do modelo, o que indica um bom ajuste da série ao modelo GARCH $(1,1)$. A especificação GARCH $(1,1)$ foi selecionada com base no critério de Akaike e seguiu a tendência de resultados de estudos anteriores, como reportado por Lamounier (2001). 
Tabela 7 - Estimativas do modelo GARCH para os retornos dos preços do Suíno, (Brasil) e Suíno (SC), 06/1984 a 11/2006

\begin{tabular}{|c|c|c|c|c|}
\hline \multicolumn{5}{|c|}{ Estim a tivas } \\
\hline Parâmetros & GARCH (1) & GARCH (2) & GARCH (3) & GARCH (4) \\
\hline \multicolumn{5}{|c|}{ Equação da média } \\
\hline C & $\begin{array}{c}-0.002206 \\
(-0.741)\end{array}$ & $\begin{array}{c}-0.000910 \\
(-0.291)\end{array}$ & $\begin{array}{c}-0.002231 \\
(-0.543)\end{array}$ & $\begin{array}{c}-0.000754 \\
(-0.184)\end{array}$ \\
\hline$\phi_{1}$ & $\begin{array}{c}0.201131^{*} \\
(2.963)\end{array}$ & $\begin{array}{c}0.216614^{*} \\
(3.129)\end{array}$ & $\begin{array}{c}0.208744^{*} \\
(3.136)\end{array}$ & $\begin{array}{c}0.255193^{*} \\
(3.891)\end{array}$ \\
\hline$\phi_{2}$ & - & 1 & $\begin{array}{c}-0.085391 \\
(-1.244)\end{array}$ & $\begin{array}{c}-0.099045 \\
(-1.515)\end{array}$ \\
\hline \multicolumn{5}{|c|}{ Equação da variância } \\
\hline$\alpha_{0}$ & $\begin{array}{c}1.85 \mathrm{E}-05 \\
(1.773)\end{array}$ & $\begin{array}{c}9.33 \mathrm{E}-06 \\
(1.272)\end{array}$ & $\begin{array}{c}3.51 \mathrm{E}-05 \\
(1.728)\end{array}$ & $\begin{array}{c}1.68 \mathrm{E}-05 \\
(1.368)\end{array}$ \\
\hline$\alpha_{1}$ & $\begin{array}{c}0.071835^{\star} \\
(3.379)\end{array}$ & $\begin{array}{c}0.050256^{*} \\
(2.937)\end{array}$ & $\begin{array}{c}0.061822^{*} \\
(3.693)\end{array}$ & $\begin{array}{c}0.034982^{*} \\
(3.105)\end{array}$ \\
\hline$\beta_{1}$ & $\begin{array}{c}0.919027^{*} \\
(58.233)\end{array}$ & $\begin{array}{c}0.936258^{*} \\
(65.487)\end{array}$ & $\begin{array}{c}0.929535^{*} \\
(77.542)\end{array}$ & $\begin{array}{c}0.951149^{*} \\
(100.689)\end{array}$ \\
\hline$\delta_{3}$ & - & $\begin{array}{c}0.000115^{\star *} \\
(1.973)\end{array}$ & - & - \\
\hline $\mathrm{O}_{4}$ & - & & - & $\begin{array}{c}0.000411^{* *} \\
(2.088)\end{array}$ \\
\hline $\mathrm{R}^{2}$ ajustado & 0.053 & 0.050 & 0.047 & 0.047 \\
\hline Akaike & -3.0232 & -3.0393 & -2.4698 & -2.4966 \\
\hline Schwarz & -2.9559 & -2.9584 & -2.3892 & -2.4025 \\
\hline
\end{tabular}

Notas:

*Significante a $1 \%$.

**Significante a $5 \%$.

Valor da estatística $\mathrm{Z}$ entre parênteses.

Equação da média: $r_{S B R t}=c+\phi_{1} r_{S B R_{t-1}}+\varepsilon_{t}$

$\operatorname{GARCH}(1): \sigma_{S B R t}^{2}=\alpha_{0}+\alpha_{1} \varepsilon_{t-1}^{2}+\beta_{1} \sigma_{t-1}^{2}$

GARCH(2): $\sigma_{S B R t}^{2}=\alpha_{0}+\delta_{3}$ Aftosa $+\alpha_{1} \varepsilon_{t-1}^{2}+\beta_{1} \sigma_{t-1}^{2}$

Equação da média: $r_{S S C t}=c+\phi_{1} r_{S S C_{t-1}}+\phi_{2} r_{S S C_{t-2}}+\varepsilon_{t}$

$\operatorname{GARCH}(3): \sigma_{S S C t}^{2}=\alpha_{0}+\alpha_{1} \varepsilon_{t-1}^{2}+\beta_{1} \sigma_{t-1}^{2}$

GARCH (4): $\sigma_{S S C t}^{2}=\alpha_{0}+\delta_{4}$ Aftosa $+\alpha_{1} \varepsilon_{t-1}^{2}+\beta_{1} \sigma_{t-1}^{2}$

Fonte: Dados da pesquisa. 
A persistência de choques na volatilidade dos retornos nos modelos é elevada, pois a soma $\alpha_{1}+\beta_{1}$ aproxima-se de 0,99 . Quanto mais próximo de 1 for o valor do coeficiente de persistência, o choque sobre a volatilidade irá se enfraquecer de maneira mais lenta e, portanto, maior será a demora do processo de reversão à média para a variância (isto é, o choque demora a dissipar).

Os coeficientes $\delta_{3}$ e $\delta_{4}$ foram positivos e estatisticamente significativos, o que confirma a hipótese de que os focos de febre aftosa em 2004-05, ao gerar restrições às exportações de carne suína, contribuíram para o aumento na volatilidade dos retornos dos preços dos produtores no Brasil e em Santa Catarina, no período.

Ao examinar os coeficientes $\delta_{3}$ e $\delta_{4}$, verifica-se que o impacto da febre aftosa na volatilidade dos preços em Santa Catarina foi três vezes maior do que no Brasil. O coeficiente $\beta$ da equação de variância dos retornos dos preços, em Santa Catarina, foi maior que na série de retornos Brasil, o que indica que choques, como o foco de aftosa, levaram tempo maior para desaparecer, ou seja, foram mais persistente em SC. Uma possível explicação para essa maior persistência do choque em SC é que, no estado, predomina a suinocultura integrada à agroindústria oligopolística, o que caracteriza a oferta de carne suína como preçoinelástica; por isso, no mercado estadual, os preços dos produtores apresentariam fortes variações para baixo, diante das retrações da demanda.

Ademais, dados os critérios de Akaike e Schwarz, os modelos GARCH (2) e GARCH (4), que incluem a variável dummy AFTOSA, ajustam-se melhor às séries dos retornos do que os modelos GARCH (1) e GARCH (3), os quais não contém a variável binária. 
A Figura 3 evidencia os resultados encontrados. Após o choque ocasionado pela aftosa, indicado pela linha tracejada, houve aumento expressivo da volatilidade, fenômeno detectado tanto na série de retornos dos preços do suíno no Brasil quanto em Santa Catarina.
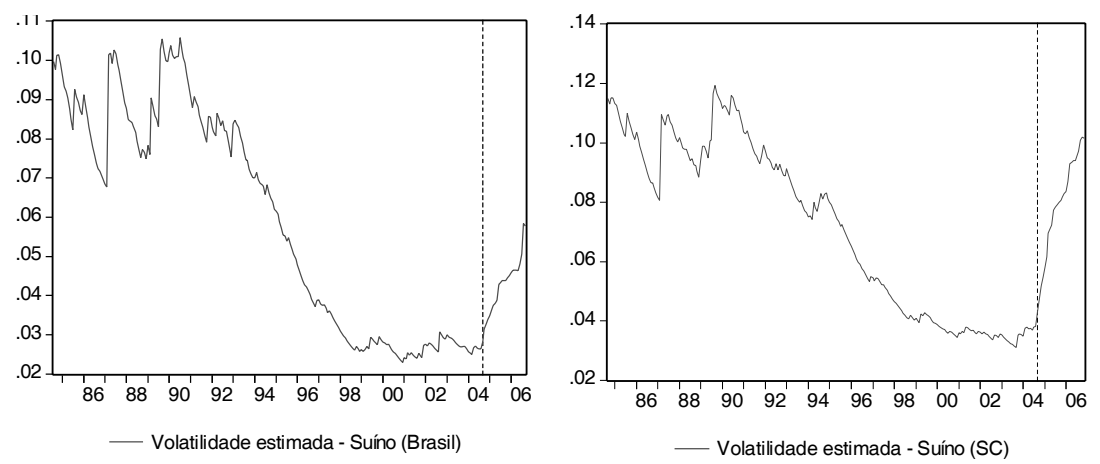

Figura 3 - Volatilidade estimada pelo modelo GARCH dos retornos dos preços, 06/1984 a 11/2006

\section{Conclusões}

Os resultados indicam que os focos de aftosa ocorridos no Brasil tiveram impacto no aumento da volatilidade dos preços recebidos pelos produtores da carne suína, o que confirma a hipótese do trabalho. O efeito de amplificação da volatilidade foi detectado tanto na série de preços nacional (Brasil) como nos retornos dos preços dos produtores de Santa Catarina, sendo maior nesse último.

O aumento da volatilidade implica maior dificuldade de os produtores perceberem a real tendência dos preços futuros, o que é agravado pelo fato de o setor não contar com nenhum mecanismo protetor (hedging) contra o risco de mercado, o que dificulta o planejamento da produção. Como a agroindústria processadora tem a alternativa de dirigir maior ou menor parcela da carne para produtos processados, a volatilidade tende a ser mais prejudicial ao segmento produtor na cadeia de carne suína. 
Do ponto de vista empresarial, torna-se estratégica a busca de novos mercados, com vistas em reduzir a grande dependência da compra da Rússia. Como a sanidade animal é um bem público, os investimentos governamentais são essenciais à maior fiscalização das fronteiras secas com países limítrofes (Paraguai, Argentina e Bolívia), à maior agilização das equipes de controle da doença, à indenização adequada dos produtores afetados e à disponibilidade de mais laboratórios para maior agilidade na realização de exames que visam detectar a presença da doença.

\section{Referências}

ABIEC/Associação Brasileira das Indústrias Exportadoras de Carnes. Estatísticas on-line, 2006. Disponível em www.abiec.org.br. Acesso em 10/2006.

ABIPECS/Associação Brasileira das Indústrias Produtoras e Exportadoras de Carne Suína. Relatório Anual, 2004, 2006, 2007.

BLAKE, A., SINCLAIR, M. T., SUGIYARTO, G. The Economy-Wide Effects of Foot and Mouth Disease in the UK Economy. Working Paper - Nottingham University Business School. 17p., 2002.

BOLLERSLEV, T. Generalized Autorregressive Conditional Heteroskedasticity. Journal of Econometrics, v.31, p.307-327, 1986.

CARVALHO, T.H., MELO, G. B., ZEN, S. Análise da Transmissão entre os Preços dos Cortes de Suínos no Varejo e os Preços Recebidos pelos Produtores no Estado de São Paulo. XLIV Congresso da Sociedade Brasileira de Economia e Sociologia Rural, Fortaleza, 23-27 de Julho, 2006.

CUDDINGTON, J.T. \& LIANG, H. Commodity Price Volatility Across Exchange Rate Regimes. Department of Economics, Georgetown University, Washington, DC, 2003. Disponivel em < http://129.3.20.41/ eps/if/papers/9802/9802003.pdf > Acesso em 18/05/2009. 
ENGLE, R. F. Autorregressive Conditional Heteroskedasticity with Estimates

of the Variance of United Kingdom Inflation. Econometrica, v.50, n.4, p.987-1007, 1982.

FARIA, R. N., BURNQUIST, H. L. Impactos da Febre Aftosa no Setor de Abates de Animais: uma análise de equilíbrio geral. XLIV Congresso da Sociedade Brasileira de Economia e Sociologia Rural, Fortaleza, 23-27 de Julho, 2006.

FGV AGROANALYSIS / Fundação Getúlio Vargas. Base de dados estatísticos. Disponível em: <http://www.iea.sp.gov.br/out/index.php $>$ Acesso em:11/2006.

HARPER, D.C. \& GOODWIN, B.K. Price transmission, Threshold Behavior, and Asymmetric Adjustment in the U.S. Pork Sector. American Agricultural Economics Association Annual Meeting, Nashville, 1999.

HSU, S. H., LEE, D. H., LIN, C. C. C. H. C., YANG, T.C. Foot-andMouth Disease on Taiwan Using a Dynamic Computable General Equilibrium Model. American Agricultural Economics Association Annual Meeting, Providence, Rhode Island, July 24-27, 25p., 2005.

ICEPA/Instituto de Planejamento e Economia Agrícola de Santa Catarina. Síntese Anual da Agricultura de Santa Catarina: 20052006. Florianópolis: Secretaria de Agricultura e Desenvolvimento Rural de SC, 2006.

IPEA - Instituto de Pesquisa Econômica e Aplicada. Base de dados estatísticos. Disponível em: < http://www.ipeadata.gov.br/ipeaweb.dll/ ipeadata?477509078> Acesso em: 10/2006. 
JARVIS, L. S., CANCINO, J. P., BERVEJILLO, J. E. The Effect of Foot and Mouth Disease on Trade and Prices in International Beef Markets. American Agricultural Economics Association Annual Meeting, Providence, Rhode Island, July 24-27, 37p., 2005.

JONES, K.G. Price Volatility and Transmission in the Hog and Pork Markets. Meeting of the Southern Agricultural Economics Association, Arkansas, Feb 5-9, 2005.

LAMOUNIER, W. M. Comportamento dos Preços no Mercado Spot de Café do Brasil: Análise nos Domínios do Tempo e da Frequiência. 2001, 207f. Tese (Doutorado em Economia Aplicada) Universidade Federal de Viçosa, MG, 2001.

LIMA, R. C. A., MIRANDA, S. H. G., GALLI, F. Febre Aftosa: impacto sobre as exportações brasileiras de carnes e o contexto mundial das barreiras sanitárias. Instituto de Estudos do Comércio e Negociações Internacionais, 31p., 2005.

LYRA, T. M. P., SILVA, J. A. A Febre Aftosa no Brasil: 1960-2002. Arquivo Brasileiro de Medicina Veterinária e Zootecnia. v.56 (5) ,p. 565-576, 2004.

MACEDO, L. O. B. Investigação dos Determinantes da Rentabilidade das Exportações de Carne Bovina Brasileira no período de 1995 a 2006. Informações Econômicas, SP, vol. 37, n. 5, 2007.

MACHADO, L. V. N., AMIN, M. M. Impacto da Febre Aftosa na Posição Competitiva do Brasil no Mercado Internacional de Carne Bovina. XLIV Congresso da Sociedade Brasileira de Economia e Sociologia Rural, Fortaleza, 23-27 de Julho, 2006.

NATCHER, W.C. \& WEAVER, R. D. The Transmission of Price Volatility in the Beef Markets: A Multivariate Approach. American Agricultural Economics Association Annual Meeting, Nashville, Tennessee, 1999. 
PITUCO, E. M., A importância da Febre Aftosa em Saúde Pública. SIC - Serviço de Informação da Carne. Centro de Pesquisa e Desenvolvimento de Sanidade Animal (Instituto Biológico), 7p., 2001.

ROH, J. S., LIM, S.S., ADAM, B. D., The Impact of Foot-and-Mouth Disease (FMD) on Hog, Pork, and Beef Prices: the Experience in Korea. Conference on Applied Commodity Price Analysis, Forecasting, and Market Risk Management. St. Louis, Missouri, April 17-18, 17p., 2006.

SHARPE, W. Capital asset prices: A theory of market equilibrium under conditions of risk. Journal of Finance, vol. 19, n.3, p. 425442, 1964.

SILVA, W. S. D., SÁFADI, T., CASTRO JR., L. G. D. Uma análise empírica da volatilidade do retorno de commodities agrícolas utilizando modelos ARCH: os casos do café e da soja. Revista de Economia e Sociologia Rural, v. 43, n. 01, 2005.

SWARAY, R. B. Volatility of Primary Commodity Prices: Some Evidence from Agricultural Exports in Sub-Saharan Africa, Discussion Papers in Economics, n.2002/06, University of York, 2002.

TSAY, R. S. The analysis of financial time series. New York: J. WILEY, 2002. 
Abstract. FMD focuses were found again inBrazil in 2004 and 2005, which caused embargo for Brazilian exports of pork meat. This paper investigates the volatility of prices received by pig producers after the FMD focus were found. Using a GARCH model, including a variable indicating FMD events, we cannot reject the hypothesis that the disease caused high pork price volatility. The conclusion is the FMD disease is related not only to losses due to embargoes but also to the increase of pork price volatility, which brings about instability to businesses and to pig producers income.

Keywords: foot and mouth disease, pork, volatility, GARCH. 
REVISTA DE ECONOMIA E AGRONEGÓCIO, VOL.7, $N^{\circ} 2$ 